\title{
Existing Dioxin Inventories Worldwide and a New Methodology to Establish Comparable and Complete Release Inventories
}

(Existierende Dioxininventare weltweit und neue Methodik zur Erstellung von vergleichbaren und vollständigen Emissionsinventaren)

[UWSF - Z Umweltchem Ökotox 13 (2) 88-94 (2001)]

\section{Heidelore Fiedler}

UNEP Chemicals, 11-13, Chemin des Anémones, CH-1219 Châtelaine (GE), Switzerland; e-mail: hfiedler@unep.ch

Four years after Decision 19/13 C of 7 February 1997 of the Governing Council of the United Nations Environment Programme (UNEP), the Stockholm Convention on POPs (persistent organic pollutants) has been signed by 91 countries and the European Commission on May 22-23, 2001. This Convention includes legally binding provisions on unintentionally produced POPs such as PCDD/PCDF. In order to assist countries to fulfill the obligations of the Convention, UNEP has published a compilation of existing PCDD/ PCDD release inventories (UNEP 1999) and is updating such information. The present status is as follows:

PCDD/PCDF are byproducts from chemical, industrial processes, almost all combustion processes and to a lesser extent from natural processes. They can occur in all release vectors: emissions to air, to water, to land, with residues and in products. So far, emission inventories published by countries are either based on nationally measured data or by application of emission factors obtained from other countries. Commonly, results were reported as toxic equivalents (TEQ). The evaluation of presently available inventories showed that the results are biased: whereas the metal producing and recycling industry is the sector with the highest PCDD/PCDF emissions in Europe, waste incineration is considered to be the major source in many other countries. Most countries report emissions to air only and do not consider the other release vectors. A further complication is that inventories do not have the same reference year. All this together makes it very difficult to compare PCDD/PCDF release inventories.

According to most recent data, $12,900 \mathrm{~g}$ TEQ of PCDD/PCDF are emitted into the atmosphere by 16 countries. Highest emissions are from the densely populated industrialized countries of the Northern hemisphere - Japan $(6,300 \mathrm{~g} \mathrm{TEQ} / \mathrm{a}$ in 1997) and the United States of America (2,888 g I-TEQ/a in 1995). Measures to reduce dioxin emissions have resulted in strong downward trends, as shown, e.g., in Germany (down from $1,210 \mathrm{~g}$ TEQ in the years $1989 / 90$ to $291 \mathrm{~g} \mathrm{I}-\mathrm{TEQ}$ in $1994 / 95$ and an estimated $<70 \mathrm{~g}$ TEQ for 1999/2000) and Japan (for 1999, the figure ranged 2260-2440). Nevertheless, potentials for further reduction have been identified.

Presently, Japan is the only country that reports PCD/PCDF emissions on the basis of WHO-TEQ, which include the coplanar and mono-ortho substituted PCB. According to the Japanese 1999 inventory the contribution from the dioxinlike PCB is between $11 \%$ and $36 \%$ of the total inventory.

So far, countries have utilized own methods to calculate their dioxin emissions and the majority has addressed releases to air only. The future Stockholm Convention on POPs will require to continuously reduce dioxin emissions. In order to assist countries in inventory making, UNEP has produced the Toolkit, a methodology to establish comparable dioxin inventories that address releases to air, water and land, with products and in residues.

\section{Emission Inventories - Current State}

(POPs - Stand der Entwicklung zur Emissionsinventarisierung)

[UWSF - Z Umweltchem Ökotox 13 (3) 165-170 (2001)]

Steffi Richter, Dagmar Kallweit and Suzanne Wiandt

Federal Agency for the Environment (Umweltbundesamt), POB 3300 22, D-14191 Berlin, Germany

Corresponding author: Dr. Steffi Richter; e-mail: steffi.richter@uba.de

\section{Scope and Background}

The measures obliged to be implemented for reduction of the impact of POPs on the environment are essential elements in some international treaties concerned with these group of substances. Recently the Stockholm Convention was signed as a legally binding instrument for action against POPs on a global scale but some other international fora address these substances too, although in specific media, for instance in relation to their long-range transboundary atmospheric pollution (UNECE protocol) or their discharge 